\title{
KEY DEVELOPMENT, APPLICATION CONTEXT AND FORMS OF TECHNOLOGY ASSESSMENT
}

\author{
[Klíčový rozvoj, aplikace kontextu a formy hodnocení technologií] \\ Marek Jemala ${ }^{1}$ \\ ${ }^{1}$ University of Nova Gorica, School of Engineering and Management, Vipavska 13, Rožna Dolina, Nova Gorica, \\ Slovenia, SI-5000 \\ E-mail:marek.jemala@ung.si
}

\begin{abstract}
The key intention of this study is to outline primary characteristics, the application context and the forms of Technology Assessment (TA). Identifying determinants and effects of a new technology usually requires an interdisciplinary approach. The final "technology picture" should be based on a broader rational consensus of the scientific discussion, but TA can also require the participation of non-experts who can bring a more comprehensive insight into the process. This study also deals with the historical characterization of TA within technology identification processes, as a part of integrated Technology management. The research was carried out based on an intensive literature study, the extensive Bibliometrical analysis especially of the Sciencedirect and the EBSCOhost databases, and several case studies.
\end{abstract}

Keywords: foresight, technology assessment, technology forecasting, technology innovation, technological literacy.

JEL classification: O14, O32, O33

Doručeno redakci: 15.2.2013; Recenzováno: 22.5.2013; 10.5.2013; Schváleno k publikování: 16.6.2014

\section{Introduction}

More complex TA requires more complex identification of technology elements, processes, links, as well as actual or potential synergies and dies-synergies, which can occur after innovation is applied. These broader relations often exceed an intra/institutional environment and more often include broader direct and indirect impacts on the environment, but also impacts of this environment on the technology (Tassey, 2009). For example, a higher demand, improved market structures, or better living standard of people, but also new environmental problems, negative legislative impacts, needs to improve business infrastructure, etc. Therefore TA should be closely linked with broader socio-economic effects of technology on its environment, especially as regards to the impact of new technology on real economic results of companies, regions and countries, and thus indirectly also on a living standard of people. Among associated effects of technology that are usually examined, there are mainly the problems of natural resources depletion, problems of food safety, safety of products for regular human use, as well as increasing pollution problems.

Thus, technological development can be more conditioned by an active support and control of the society, for example by the social technology acceptance, which is primarily manifested by a market demand, but also by particular governmental and regional policies and promotions. There are reciprocal links in terms of development of the society versus technological development. Therefore it is necessary systematically to monitor and assess these and related socio-environmental links and their dynamics to adequately support and benefit from socially and environmentally acceptable technologies. Thus, TA has become a macro discipline under the control of governmental institutions and the general public watch.The key intention of this study is to outline methodically and analytically the main specifics, links and determinants of TA processes that are often inaccurately specified or confused, for example with processes of Technology foresight or Forecasting. 


\section{Short development and main impacts of technology assessment}

„,Technology assessment should be not primarily focused on technology foresight or planning. It is a process in which participants have a right to ask questions and to seek for answers based on factual information that must be obtained through multidisciplinary analyses. As far as important information is not available, there must be carried out further research. But, Technology assessment should be assistance not a substitution to Strategic management. "

(Emilio Q. Daddario, Director of OTA, USA, 1975)

If we look at the development of Technology identification processes, including TA, through the Bibliometrical analysis, then it is obvious that the most developed process among them is TA, followed by technology development. From the time perspective, there have been again the most developed processes of TA, but also of the technology research, since about the 1970s. The beginnings of 'systematic TA' can be found in connection with the establishment of the Office for Technology Assessment at the U.S. Congress (1972-1995) (Schevitz, 1993). This office was created based on a social demand with one major task, to assess potential impacts of planned and emerging technologies, as there were in public concerns regarding risk impacts of technological development. Since that time, TA has increasingly been connected with R\&D, public affairs, and related policies, with the focus on optimal and safe technological development and applications in various sectors. Since the 1990s, the central determinants of TA processes have become optimal participation and process effectiveness (Grunwald, 2006). Currently, there are the main qualitative criteria of TA: sustainable socio/environmental development, public safety, early warnings against technological and environmental risks, or ethical applications of technology. Increasing social awareness about specific impacts of science and technology (S\&T) has increased the interest mainly in health and environment friendly products and technologies, and thus created conditions for better social shaping of technological development. The large part of all the analysed TA processes creates the TA in the health sector and medical technologies. These are mainly observed by the public, which explains the increased number of professional publications in this field. The least developed are the processes of Technology analysis and Foresight, even over the time. This may be due to the often confused Technology analysis, TA, Technology foresight (even by experts), which are practically follow-up processes. In the graph we can see the main share of TA processes to the overall processes of technology identification, as well as their similar development. (Table 1)

Table 1: Development of technology identification processes - Number of scientific articles ${ }^{1}$

\begin{tabular}{|c|c|c|c|c|c|c|c|c|c|c|c|c|c|c|}
\hline \multirow{2}{*}{ Years } & \multicolumn{2}{|c|}{-1970} & \multicolumn{2}{|c|}{-1980} & \multicolumn{2}{|c|}{-1990} & \multicolumn{2}{|c|}{-1995} & \multicolumn{2}{|c|}{-2000} & \multicolumn{2}{|c|}{-2005} & \multicolumn{2}{|c|}{-2010} \\
\hline & $S c D$ & $E B h$ & $S c D$ & $E B h$ & $S c D$ & $E B h$ & $S c D$ & $E B h$ & $S c D$ & $E B h$ & $S c D$ & $E B h$ & $S c D$ & $E B h$ \\
\hline Tech. analysis & - & - & 1 & 1 & 7 & 2 & 14 & 6 & 27 & 9 & 39 & 13 & 60 & 20 \\
\hline Tech. assessment & 1 & 2 & 99 & 60 & 297 & 386 & 440 & 730 & 597 & 1064 & 749 & 1453 & 1105 & 1934 \\
\hline Tech. foresight & - & - & - & - & - & - & 4 & 4 & 20 & 10 & 30 & 21 & 51 & 27 \\
\hline Tech. planning & 1 & - & 5 & 1 & 16 & 7 & 29 & 18 & 37 & 31 & 51 & 46 & 63 & 62 \\
\hline Tech. research & 2 & 1 & 12 & 3 & 65 & 14 & 129 & 24 & 189 & 40 & 260 & 69 & 340 & 123 \\
\hline Tech. development & - & - & 18 & 8 & 146 & 31 & 297 & 59 & 557 & 120 & 856 & 262 & 1280 & 446 \\
\hline Sum & 4 & 3 & 135 & 73 & 531 & 440 & 913 & 841 & 1427 & 1274 & 1985 & 1864 & 2899 & 2612 \\
\hline
\end{tabular}

Source: Sciencedirect, 2012; EBSCOhost, 2011

\footnotetext{
${ }^{1}$ Table 1 was compiled based on the Bibliometrical analysis, these stated numbers refer to the numbers of scientific articles published in refereed scientific journals registered in the Sciencedirect (ScD) and EBSCOhost (Ebh) databases.
} 


\subsection{Key goals and initiatives of technology assessment}

The qualitative criteria are the most important at the forefront of TA, i.e. mainly with the ability to scale their impacts and benefits (Grunwald, 2006), as far as to the need for transforming them into more measurable quantitative criteria (cost, savings, VA, income, profit etc.) (The other criteria of TA will be further explained in the section 3.2.) These criteria are the basis for setting the goals of TA. Currently, the key goals of TA include:

- Identification of medium and long term direct and indirect technology impacts.

- Minimizing unsuitable investment, costs and activities associated with technology development.

- Identification of broader alternatives for technology development.

- Estimation of market possibilities associated with selling products, services, or technology, as well as economic results related to the application of technology.

- Identifying related needs and problems of a business, a region, or an industry. (Krück et al., 2003)

- Recognition of economic, social, technical and other trends in the environment.

- Providing relevant information for strategic decision making for business, public, or governmental institutions.

- Increasing public awareness of a new technology and products and obtaining greater acceptance for a specific technology. Etc.

Among the leading institutions in the TA field belong: European Technology Assessment Group, European Technology Assessment Network, and International Association for Impact Assessment. All these bodies are the international networks of so-called the best practice, i.e. skills and know-how for the assessment of impacts related to technology innovation, and for the better support of S\&T policies, programs, plans and projects. One of the key specifics of these organizations is broad participation of various stakeholders, which can provide better opportunities for exchanging experience and improving complexity of TA processes. The main activities of these institutions typically include:

(1)Developing approaches and practices for the comprehensive and integrated impact of TA.

(2) Improving assessment practice and methods for more practical applications.

(3) Sharing information, preparing technological publications and organizing professional meetings. (Cagnin et al., 2008)

(4) Providing expert advisory on the basis of close cooperation.

(5) Promoting training focused on TA and spread of public awareness about these processes and their results.

A positive example is the longer-term TA initiative at the U.S. Congress, which has focused primarily on social, environmental and economic utilization of new technologies, while each approval of a certain technology should be preceded by detailed systemic analyses and answering key questions like:

- What are the main consequences of applying the technology for economic development of a company, a region, or an industry?

- How can a technology help improve a situation in the environment?

- How can the progress in technology innovation affect the development in the society?

- How will technology products and equipment be recycled and disposed of after their use? (Vasanthi - Shekhar, 2004) Etc. 
TA can also be a functional part of regional, industrial, and national S\&T policy setting and programs, Technology forecasting or Foresight. For example, the German study: Technology at the threshold of the $21^{\text {st }}$ century was the foresight study, but included also TA and technology forecasting processes. The involved experts had to analyze, assess, and forecast positive and negative impacts of new technologies in Germany. (UNIDO, 2005) The project on this Foresight included the processes of TA and Technology forecasting. For better synergetic purposes, it is, however, useful to differentiate clearly these processes. Technology foresight is primarily focused on identifying and planning wider technological and related socio-economic trends and risks in a longer period, i.e. 5 years and more. (EFMN, 2010) Technology forecasting is usually based on experts' estimation of specific technology trends and risks for about 1 to 3 years. And, TA is largely focused on assessing medium-term impacts of technologies and their determinants. (Jemala - Svatý, 2010) Usually, Technology foresight and Forecasting require TA in their analytical phases. (Figure 1)

Figure 1: Key differences and links between Technology assessment, Forecasting and Foresight

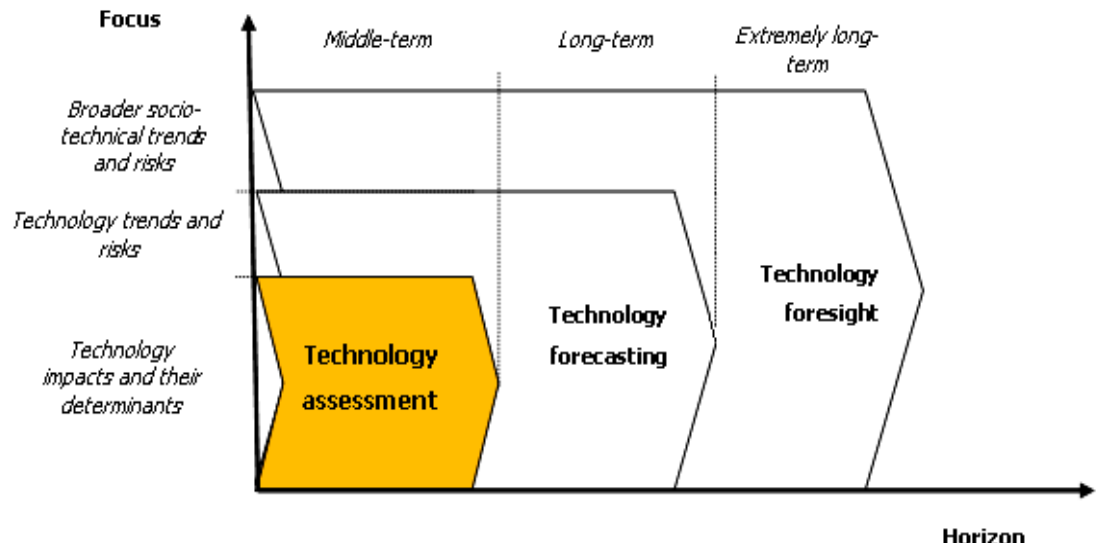

Source: own design

\subsection{Key impacts of technology applications}

High-tech systems usually require a more multidisciplinary and more complex approach not only to their R\&D, manufacturing, but also to TA. This approach should enable to identify and assess more complex effects of each technology application. These can be positive or negative, current or expected, and direct or indirect (black and red lines). If we want to assess more comprehensively and then to upgrade a technology, it is necessary to identify adequately these effects/impacts and links between them. Any of key technology impacts detected, whether on an internal or external environment, then can offer several opportunities for better technology innovation (I1-I12) (Figure 2): 
Figure 2: Key impacts of technology applications and its innovative possibilities - Innovative Future Wheel

Source: own design

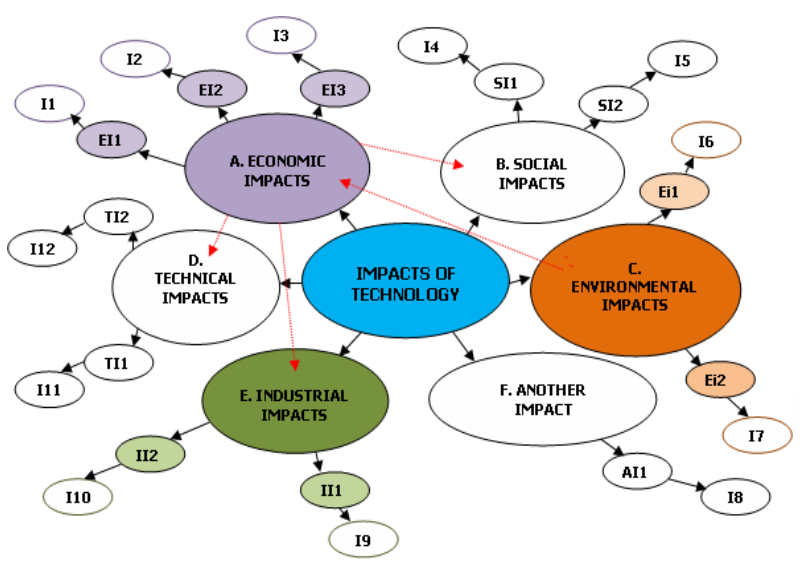

A. An economic impact of an improved technology is usually manifested by more efficient production, quicker market penetration, higher sales and revenues for a company, industry and subsequently for a state budget. This can have an indirect impact on a living standard, but also on possible new investment of the company, for example for the modernization of its technology park. In a negative sense, the more complex technology, possibly the higher costs, more difficult management, more demanding staff training, maintenance as well as possible problems with the waste disposal, etc.

B. A social impact of an improved technology may be in easier and safer implementation and better use of the technology and in improved social relations through the new technology (e.g. the Internet, a mobile phone, a safer car, etc.). Secondary effects may be in an improved quality of life through the better use of products and services.

C. An environmental impact in a positive sense may be in more environmentally acceptable production, better waste disposal and a cleaner environment. In a negative sense, it can be higher environmental pollution, increase of noise, or depletion of natural resources. Secondary effects mean the additional costs to eliminate these negative problems, and a greater burden on a business and public budget.

D. A technical impact can be manifested by better flexibility, modularity, efficiency of production technology and its equipment and by a lower labor difficulty of a production process. This allows adopting business processes more flexibly to needs of customers, reducing the costs, and a burden on the environment, etc.

Each TA should be a systemic and systematic activity that enables to examine short and long term technological possibilities, effects, relations between them, their impacts on internal environment (enterprise, a household, or an institution) and external environment (the society, a region, the environment, culture, etc.). Such TA should enable to obtain better information for better technology related decisions and policy-making of various institutions, for better technology development, restrictions, or prohibition, etc. In order to assess adequately a technology, it is necessary to ensure wider participation of various people (experts and laymen), to prepare appropriate assessment conditions and information, and to select appropriate methods and objective criteria. This process is usually highly organizationally and financially demanding, therefore, it can require a broader form of cooperation within a joint alliance or venture, industrial, regional or international cooperation, and to pool resources and capacities to make the TA process more objective and effective (Reuzel et al., 2001). For these reasons, TA is often a politically organized process also focused on planning S\&T policies. 


\section{Key steps, forms and criteria of technology assessment}

The main problem to the wider application of TA processes especially in SMEs is the lack of the necessary methodology, although there are various institutional recommendations, or procedures of how to implement and perform TA. For many SMEs is a professional help in this context often financially inaccessible. One of the institutions engaged in creating the unified TA methodology is the Association of German Engineers (VDI), which provides the helpful guidelines for implementation of TA processes (VDI, 1991). The nature of these guidelines is the distribution of TA processes throughout the following steps:

A. Structuring and identifying technology issues, features and links: This implies a breakdown of a technology problem on its parts and determinants and their precise specifications. System constraints should be fixed, there must be adequately identified and analyzed procedural elements, their links and necessary resources. In this phase of TA, it is necessary to establish a process timetable, an assessment team, and to approve TA criteria.

B. Effects estimation of the technology change: The second step includes the estimation of potential effects of technological innovation. (Dienel, 2002) This is largely carried out through established expert panels, which can provide a wider public debate regarding positive and negative impacts of a new technology.

C. Technology Assessment: The third step should provide assessment of these effects (within an estimated timescale of technology applications) based on the specified criteria. This assessment can be realised by using IT simulation/modelling, but also supported by a wider public debate during expert panels on the acceptability of the technology.

D. Strategic decision on the new or upgraded technology is a matter of corporate management and investors, who should be adequately familiarized with complex aspects of the technology application before their decision. (Ludwig, 1998) Strategic decisions should be made on the basis of proposed program implementation. (Jemala, 2008)

This simplified process of TA is more or less universal and is usually applied for different types of technology applications. A wider public debate is more related to technologies that have a direct impact on human health or the environment (Biotechnology, Nanotechnology, Nuclear energy, Mobiles integrated circuits, etc.). For example, key objectives of the Exploration Systems Architecture Study (ESAS) within the U.S. Space Exploration Vision enable to identify and assess key technologies necessary to improve the reference exploration systems and to prioritize near-term and far-term technology investment. The investment recommendations include the budget, schedule, and program allocations to improve the technologies required for the exploration architecture. The three major steps of this TA were:

a) To identify what technologies are required and when they need to be available to support the development projects,

b) To develop and implement an objective technology prioritization/planning process,

c) To develop research and technology $(R \& T)$ investment recommendations which existing projects should proceed and which new projects should be established.

The main ground rules and assumptions used for this TA are very methodological:

- All technology innovation shall be directly traceable to architecture requirements.

- Technologies shall be developed to the technology readiness level by a preliminary design review.

- Technology priorities shall receive a funding profile.

- The exact percentage of each programme budget shall be reserved for programme management.

- Funding wedges shall be included for future R\&T requirements, etc. (NASA, 2011) 


\subsection{Key forms of technology assessment}

If a company decides to upgrade its existing technology, this process usually starts by identifying bottlenecks of this technology (Problem-oriented or Problem-based TA). Problem-oriented TA can be designed to remedy problems of existing technologies (inefficiency, dangerous applications, outdated components, etc.). This process should be based on the assessment of selected criteria for a better application of the technology. This TA usually begins with setting criteria like: functionality, safety and efficiency, followed by organizational and legal criteria, and criteria for ethical applications of the technology (Decker - Ladikas, 2004). For example, Managing Agricultural Water Impacts TA has sought to analyze the impacts of agricultural water use in the USA and to propose solutions for more effective management of agricultural water resources. Among the model objectives of this problem-oriented TA belonged: identification of the problem as quantitatively as possible, to provide analyses and a context for the problem aspects, to describe direct and indirect impacts of the problem, to examine technologies available to solve this problem, to discuss available policy tools, and to predict the first and other impacts of the potential technology and policy solutions. (Covalla et. al, 2001) Usually, conventional TA methods are required to be embedded in a more problem-based approach, whereby an appropriate process of the problem analysis should take place before the design of technology innovation. (Moret-Hartman, 2008) The problem-based TA requires to set the level of problem structuring and activities needed to analyse the problem. The problem-based TA can provide more contextual consideration of technology innovation.

The interesting approach is called Interactive $T A$ and it is aimed at influencing an innovation process based on early interactions between stakeholders. Interactive TA is a form of participative TA, which differs from traditional TA, because it does not seek to estimate or accommodate impacts of the technology, but rather to exert leverage on its development (Marris et al., 2006). Interactive TA should link researchers, the industry, and the related society. The process is usually based on the creation of a small group of evaluators (10 to 15). The group focuses on the subject of TA, develops questions it wishes to raise, analyses different dimensions of the problem, and compiles a report. The report creates a support for decision makers (Joly - Rip, 2007). This TA should also deal with ethical problems associated with subjective preferences, values and patterns of participants. Interactive TA requires active cooperation of stakeholders based on wider and more open communication. (Reuzel et al., 2001) For example, The French Institut National de la Recherche Agronomique (INRA) used the Interactive TA (The Field Trial of Genetically Modified Grapevines at INRA-Colmar) to integrate public and private opinions regarding genetically modified grapevines. In the course of 7 years work, the local monitoring committee of the project built the research-action programme, which allowed changing the initial genetically modified grapevine research test, as well as developing innovative trials on the environmental impacts and organic viticulture. (Lemaire et. al, 2010) Interactive TA is often applied in medicine, agriculture, or food industry, where a significant determinant of new technology or product innovation is a public opinion.

Another form of technology assessment is called Constructive TA. This TA emphasizes proper selection of participants for the process and is aimed to secure their constructive interactions. TA is not only about analyzing and evaluating technology, but also about obtaining new knowledge of this technology and its impacts. Socio-technical mapping should be a key step in any TA exercise; and, Constructive TA can be a starting point of the sociotechnical dynamics analysis. For example, the realization of the Constructive Technology Assessment of Nanotechnology in the Netherlands was based on the request of Dutch 
nanotechnologists. This Constructive TA included: nanotechnology expectations agendabuilding, preparing possible socio-technical scenarios, the analysis and unification of TA methodology, creating alliances and networks between various stakeholders, and developing so-called 'emerging irreversibilities for the analysis of nano-districts in Europe. (Rip, 2005) In this context, there are three main specifics of Constructive TA:

- Constructive TA should identify possible future disruptive impacts of new technologies, not only identify current impacts of R\&D and normal operations.

- TA should provide qualified information, learning and improving all capabilities associated with TA. (Genus - Coles, 2005)

- This TA should be a kind of specific testing and feedback for further improvement of a technological system, etc.

Real-time TA can support more timely and contextually sensitive innovation by the real-time technology impacts mapping. This TA can improve opportunities for better strategic innovation, communication and early warnings. Its technology and choice components can provide a mechanism for the better socio-technical awareness and its more reflexive incorporating into innovation. (Guston - Sarewitz, 2002) There are often long time and financial lags between development and diffusion of innovation (mainly innovation such as nanotechnology or biotechnology), as well as lags of complex understanding of their wider impacts and risks. These unrecognitions may take several years and may cause large economic losses: for example, it is known that the toxicity testing of the manufactured nanoparticles currently available in the USA alone will cost between $\$ 250$ million and $\$ 1,2$ billion and take 30-50 years to complete. (Owen - Goldberg, 2010) Therefore, TA must have more real-time features and must be placed in the actual and expected context of the innovation landscape that is usually rapidly changing. This TA is based on the idea that TA processes should be realised simultaneously, as they can be mutually supportive, and therefore should be fully integrated within the innovation process. Real-time TA processes may consist of four parts:

a) The first part is development of analogical case studies by studying past examples of transformational innovation that can help develop frameworks for anticipating future interactions between the society and a new technology.

b) The second part is to map the resources and capabilities of relevant $\mathrm{R} \& \mathrm{D}$ trends to specify key participants and their roles and the organizational structure of TA.

c) The third part is to monitor changing knowledge, perceptions, and attitudes among various stakeholders to improve the quality of communication about the innovation.

d) And the fourth part should include individual and participatory assessment of potential impacts of a new technology.

The main role of Future-oriented TA (FTA) is to analyse and assess possible future impacts of the technology on society and the environment, to support better policy making processes and a social debate by providing goals and non-partisan information. The mentioned EU project (Technology Assessment in Europe: Between Method and Impact) have been linking the main parliamentary and non-parliamentary institutes of TA in Europe, and have enabled to devise a common basis on which FTA projects can be assessed upon. Within the project the detailed typology of impacts of FTA has been developed in three dimensions: an impact in the dimension of knowledge used in policy making or public debates; an impact in the dimension of forming opinions/attitudes of actors involved in the debate; and an impact in the dimension of initializing actions taken by policy makers or other actors. (Ladikas - Decker, 2004) These impact dimensions have been juxtaposed to three dimensions ( $3 \times 3$ matrix) of the particular issues of FTA-projects. In the same time, three main categories of determinants have been 
identified: institutional setting; technology policy making culture; and the structure and state of an innovation process.

If we look at the development of technology assessment forms based on the Bibliometrical analysis, then Constructive TA is the most developed method. The reason may be in the fact that Constructive TA is not only about analyzing and evaluating technology, but also about obtaining new knowledge of the technology and its impacts. The second most developed method is Real-time TA, however, after the year 2000. The third most common form of TA is Interactive TA. This enables real-time technology impacts mapping that is highly needed in the current turbulent business environment. The particular conclusion in this context is that the individual forms of TA have been applied after the year 2000, because of the general rise in importance of technology impacts after the year 2000. (Table 2) Various forms of TA are often combined depending on a technology and related circumstances. A more complex technology requires more complex TA processes.

Table 2: Development of technology assessment forms - Number of scientific articles ${ }^{2}$

\begin{tabular}{|l|c|c|c|c|c|c|}
\hline \multirow{4}{*}{} & \multicolumn{6}{|c|}{ Years } \\
\cline { 2 - 8 } & \multicolumn{2}{|c|}{$\mathbf{1 9 9 0}$} & \multicolumn{2}{|c|}{$\mathbf{2 0 0 0}$} & \multicolumn{2}{|c|}{$\mathbf{2 0 1 3}$} \\
\cline { 2 - 8 } & $S c D$ & $E B h$ & $S c D$ & $E B h$ & $S c D$ & $E B h$ \\
\hline Problem-oriented TA & 0 & 0 & 0 & 0 & 1 & 0 \\
\hline Interactive TA & 1 & 0 & 1 & 1 & 20 & 7 \\
\hline Constructive TA & 1 & 2 & 47 & 8 & 189 & 27 \\
\hline Real-time TA & 0 & 0 & 0 & 0 & 41 & 3 \\
\hline Future-oriented TA & 0 & 0 & 0 & 0 & 4 & 1 \\
\hline
\end{tabular}

Source: Sciencedirect, 2013; EBSCOhost, 2013

\subsection{Key criteria used for technology assessment}

In addition, we can identify Systematic or Project TA (Ludwig, 1998), TA in a R\&D phase, in a phase of application, or a technology downturn phase, Exploratory or Normative TA, Corporate, Industrial, Regional, National, or International TA, Individual or Cluster-based $T A$, etc. However, TA is always a specific process depending on the specific technology, conditions, objectives, values and decision-making criteria. But, there are some general criteria and determinants, which must meet every technology and follow every TA:

- The technology must be effective. This effectiveness must be scientifically confirmed, and must also be documented so as to the related health and environmental aspects of its application. Efficiency of the technology must be confirmed by comparison with another comparable technology or the older technology (by R\&D and the operating costs, value added, or performance).

- The technology must be functional, justified and must bring wider social benefits than the older one.

- The technology must be safe, socially and environmentally acceptable. Safety aspects mainly include safe applications of the technology, but also safety of related products, services, appropriate disposal of waste and emissions.

- The technology must allow its objective controllability, evidence and structuralization in sub-technologies, processes, functions and their determinants, which must be justified as

\footnotetext{
${ }^{2}$ Table 2 was compiled based on the Bibliometrical analysis, these stated numbers refer to the numbers of scientific articles published in refereed scientific journals and books registered in the Sciencedirect $(\mathrm{ScD})$ and EBSCOhost (Ebh) databases.
} 
well.

- The technology must allow its innovativeness and change, especially in the case of its sudden adverse effects, inefficiency, or must allow its development and enlargement, in the case of its positive effects (Loveridge, 2009).

- And, the technology must be legally authorized by valid patents, licenses or specific norms and standards before its application. Etc.

TA should result in a written summary of values and impacts of a technology, but also of adverse consequences of its application. It is inaccurate if these values are only preferences of evaluators. And, it is necessary to separate the overall complex value of the technology from its effectiveness. Effectiveness of the technology is associated with input/output relations for the owner of the technology, while a value of the technology is linked to wider internal and external benefits of its application. Therefore, TA should be more focused on the overall value of the technology. Among the other characteristics that every TA should meet:

- TA requires formulation of common standards and values before the process of TA begins (Reuzel et al., 2001), as well as the establishment of appropriate process culture.

- TA must provide an objective picture of the technology assessed, without any bias or promotion of specific personal interests (Grunwald, 2006).

- TA must be based on scientific/technical/capital independence, especially regarding sideeffects of investors', shareholders' or governmental institutions interventions.

- And, TA should lead to the creation of better social relations with various stakeholders and raise a broad public debate regarding advantages and disadvantages of the technology applications. This can not only bring better complexity, flexibility and timeliness of TA, but also higher requirements on ethics and culture of TA.

\section{Conclusion}

The beginnings of systematic participative TA can be found in connection with the establishment of the U.S. Office for Technology Assessment in the 1970s. Gradually, optimal participation, process effectiveness, later sustainable socio-environmental development, public safety, early warnings, or ethical applications of technologies have become the central determinants of TA. TA may be considered as a specific kind of interdisciplinary research and support for scientific and technological plans and policies (Grunwald, 2006). Each TA should have a passive content, i.e. assessment of past and present technological processes, and an active content, i.e. assessment of impacts of future technologies and their expected determinants. The most frequently applied methods for TA are SWOT analysis, Morphological analysis, Benchmarking, Multi-criteria analysis, Modelling and simulation, Questionnaires, Indicators analysis, Econometrics (Pesaran - Wickens, 1999), Regression analysis or Petri-nets. Among the most used forms of TA there are: Constructive TA, Realtime TA, and Interactive TA. However, forms of TA are usually combined, based on technology requirements and circumstances of the process.

The main problem associated with TA is its improper application, however, just for the lack of necessary methodology (Hansen, 2006), nevertheless, there are various institutional recommendations, or procedures how to implement TA. There has also raised the problem how to identify and evaluate impacts of highly complex and aggregated system determinants called entities. Proper evaluation of entities is virtually impossible only by applying the traditional methods of TA, without identifying broader synergies and uncertainties. One of the solutions to ensure better TA of entities is to use the set of tools called Fuzzy logic (Desel Juhás, 2001), but this is a difficult expert process, which is not usually applicable in SMEs. (Waine, 2007) More complex technologies require more complex TA solutions. Therefore, 
TA trends include the need to extend individual, regional and national TA activities to the international level. Even SMEs may participate in such international TA cooperation that can enable them to prepare better more comprehensive innovative solutions. This international cooperation may also prevent duplication and help setting the common standards for the unified TA legislation, which can have an important impact on a subsequent socioenvironmental quality and sustainability.

\section{References}

[1] CAGNiN, C., M. KEENAN, R. JOHNSTON, F. SCAPOLO and R. BARRÉ, 2008. Future-Oriented Technology Analysis: Strategic Intelligence for an Innovative Economy. Berlin/Heidelberg: Springer. ISBN 3642088368.

[2] COVALLA, E. et al., 2001. Managing Agricultural Water Impacts. North Carolina State University [online]. [accessed May 5, 2011]. Available on: http://wingolog.org/writings/water/water.pdf

[3] DADDARIO, E. Q., 1975. Annual Report to the Congress by the Office of Technology Assessment: March 15, 1975. The Office of Technology Assessment [online]. [accessed May 14, 2011]. Available on: http://www.fas.org/ota/reports/7500.pdf

[4] DECKER, M. and M. LADIKAS, 2004. Bridges between Science, Society and Policy: Technology Assessment - Methods and Impacts. Berlin/Heidelberg: Springer-Verlag. ISBN 3540212833.

[5] DESEL, J. and G. JUHÁS, 2001. Lecture Notes in Computer Science. Berlin/Heidelberg: Springer. ISBN 3-540-42662-0.

[6] DIENEL, P. C., 2002. Die Planungszelle. Der Bürger als Chance. Opladen: Westdeutscher Verlag. ISBN 3531330284.

[7] EBSCOHOST, 2011. Research Database. EBSCOHOST [online]. [accessed March 22, 2011]. Available on:

http://web.ebscohost.com/ehost/search?vid=2\&hid=5\&sid=3bcae00f-4fa3-4c9b-96227f89daed5d59\%40sessionmgr14

[8] EBSCOHOST, 2013. Research Database. EBSCOHOST [online]. [accessed February 13, 2013]. Available on:

http://web.ebscohost.com/ehost/search/advanced?sid=84c1d281-4be3-41ae-8f2a$17 \mathrm{a} 8 \mathrm{cf0}$ a5dda\%40sessionmgr110\&vid=29\&hid=108

[9] EFMN, 2010. Database of Foresight initiatives. EFMN [online]. [accessed January 10, 2010]. Available on: http://www.foresightnetwork.eu/index.php?option=com_wrapper\&Itemid=56

[10] GENUS, A. and A. M. COLES, 2005. On constructive technology assessment and limitations on public participation in technology assessment. Technology analysis and strategic management, 17(4), 433-443. ISSN 0953-7325.

[11] GRUNWALD, A., 2006. Science independence as a constitutive part of parliamentary technology assessment. Science and public policy, 33(2), 103-11., ISSN 1471-5430.

[12] GUSTON, D. H. and D. SAREWITZ, 2002. Real-time technology assessment. Technology in Society, 24(1-2), 93-109. ISSN 0160-791X.

[13] HANSEN, J., 2006. Operationalising the public in participatory technology assessment: A framework for comparison applied to free cases. Science and public policy, 33(8), 571-584. ISSN 1471-5430. 
[14] JEMALA, M. and F. SVATÝ, 2010. Ontológia foresightu: Podnety pre tvorbu vízie SR na báze metodiky foresightu. Bratislava: Ekonóm. ISBN 802252879X.

[15] JEMALA, L., 2008. Podnikatel'ský manažment a marketing. Bratislava: Vydavatel'stvo STU. ISBN 8022728607.

[16] JOLY, P. B. and A. RIP, 2007. A timely harvest. Nature, 450(8), 1-11. ISSN 00280836.

[17] KRÜCK, C. P., N. MALANOWSKI and A. ZWECK, 2003. Technology assessment and business community: Trends and innovative developments in western countries. Futures Research Quarterly, 19(3), 45-52. ISSN 8755-3317.

[18] LEMAIRE, O., A. MONEYRON and J. E. MASSON, 2011. "Interactive Technology Assessment" and Beyond: the Field Trial of Genetically Modified Grapevines at INRAColmar. PLOS Biology [online]. [accessed June 14, 2011]. Available on: http://www.plosbiology.org/article/info\%3Adoi\%2F10.1371\%2Fjournal.pbio.1000551

[19] LADIKAS, M. and M. DECKER, 2004. Assessing the Impact of Future-Oriented Technology. Institute for Technology Assessment and System Analysis [online]. [accessed July 1, 2011]. Available on: http://foresight.jrc.ec.europa.eu/fta/papers/Session\%204\%20What\%27s\%20the\%20Use/ Assessing\%20the\%20Impact\%20of\%20Future-Oriented\%20Technology.pdf

[20] LOVERIDGE, D., 2009. Foresight: The Art and Science of Anticipating the Future. NY: Routledge. ISBN 0415398150.

[21] LUDWIG, B., 1998. Fuzzy logic applications in technology assessment studies. Journal of Intelligent and Fuzzy Systems, 1(6), 375-388. ISSN 1064-1246.

[22] MARRIS, C., P. JOLY and A. BERTRAND, 2006. Choosing participants for a constructive technology assessment exercise: dilemmas and consequences. In: Proceedings of the PATH Conference, Edinburgh, Scotland, 4-7 June 2006.

[23] MORET-HARTMAN, M., 2008. Problem structuring in health technology assessment. Radboud Universiteit Nijmegen [online]. [accessed July 1, 2011]. Available on: http://repository.ubn.ru.nl/bitstream/2066/65603/1/65603_probstinh.pdf

[24] NASA, 2011. Technology assessment. NASA [online]. [accessed June 29, 2011]. Available on: www.nasa.gov/pdf/140640main_ESAS_09.pdf

[25] OWEN, R. and N. GOLDBERG, 2010. Responsible Innovation: A Pilot Study with the U.K. Engineering and Physical Sciences Research Council. Risk Analysis, 30(11), 16991707. ISSN 1539-6924.

[26] PESARAN, H. M. and M. WICKENS, 1999: Handbook of Applied Econometrics: Macroeconomics. Oxford: Wiley-Blackwell. ISBN 0631215581.

[27] REUZEL, R. P. B., G. J. VAN DER WILT, H. A. M. J. TEN HAVE and P. F. DE VRIES ROBBÉ, 2001. Interactive Technology Assessment and Wide Reflective Equilibrium. Journal of Medicine and Philosophy, 26(3), 245-261. ISSN 1744-5019.

[28] RIP, A., 2005. Technology Assessment as Part of the Co-Evolution of Nanotechnology and Society: the Thrust of the TA Program in NanoNed. In: Proceedings of the Nanotechnology in Science, Economy and Society, Marburg, 13-15 January 2005.

[29] SCHEVITZ, J., 1993. OTA at 20: On the starting block. TA-Datenbank-Nachrichten. 22(3), 3-14. ISSN 0943-8246. 
[30] SCIENCEDIRECT, 2012. Research Database. SCIENCEDIRECT [online]. [accessed June 15, 2012]. Available on:

http://www.sciencedirect.com/science?_ob=MiamiSearchURL\&_method=requestForm \&_btn=Y\&_zone=TopNavBar\&_origin $=$ browse＆_acct $=$ C000051056\&_version $=1 \&$ _ur lVersion=1\&_userid=1052399\&md5=107b8dcb923b70ac4addc 80473615754 .

[31] SCIENCEDIRECT, 2013. Research Database. SCIENCEDIRECT [online]. [accessed February 13, 2013]. Available on:

http://www.sciencedirect.com/science?_ob=MiamiSearchURL\&_method=requestForm \&_btn $=$ Y\&_zone $=$ TopNavBar\&_origin $=$ srch_form\&_acct $=$ C000051056\&_version $=1 \&$ _urlVersion=1\&_userid=1052399\&md5=6df163298987bcdd17ed6eb33b5385a0

[32] TASSEY, G., 2009. The Roles and Economic Impacts of Technology Infrastructure. NIST [online]. [accessed November 13, 2009]. Available on: www.nist.gov/.../Measurement_Infrastr_Roles_Impacts_v3.pdf

[33] VASANTHI, N. and N. CH. SHEKHAR, 2004. Technology innovations and its social impacts. In: Proceedings of the IAMOT conference, Washington D.C., September 2004.

[34] VDI, 1991. Technikbewertung - Begriffe Und Grundlagen. In Die Vdi Richtlinie 3780. Institut für Philosophie [online]. [Accessed April 4, 2010]. Available on: www.Philosophie.Uni-Karlsruhe.De/.../488_Maring_Lse_1505_2008.pdf

[35] WAINE, T., 2007. Fuzzy Logic. St Albans: Camra Books. ISBN 1852492325. 